\title{
Fully dense, non-faceted 111-textured high power impulse magnetron sputtering TiN films grown in the absence of substrate heating and bias
}

\author{
Martina Lattemann, Ulf Helmersson and J.E. Greene
}

\section{Linköping University Post Print}

N.B.: When citing this work, cite the original article.

Original Publication:

Martina Lattemann, Ulf Helmersson and J.E. Greene, Fully dense, non-faceted 111-textured high power impulse magnetron sputtering TiN films grown in the absence of substrate heating and bias, 2010, Thin Solid Films, (518), 21, 5978-5980.

http://dx.doi.org/10.1016/j.tsf.2010.05.064

Copyright: Elsevier

http://www.elsevier.com/

Postprint available at: Linköping University Electronic Press

http://urn.kb.se/resolve?urn=urn:nbn:se:liu:diva-74698 


\section{Accepted Manuscript}

Fully dense, non-faceted 111-textured high power impulse magnetron sputtering TiN films grown in the absence of substrate heating and bias

M. Lattemann, U. Helmersson, J.E. Greene

PII:

S0040-6090(10)00734-0

DOI: $\quad$ doi: $10.1016 / j . t s f .2010 .05 .064$

Reference: $\quad$ TSF 27624

To appear in: $\quad$ Thin Solid Films

Received date: 29 March 2010

Revised date: $\quad 5$ May 2010

Accepted date: $\quad 8$ May 2010

Please cite this article as: M. Lattemann, U. Helmersson, J.E. Greene, Fully dense, nonfaceted 111-textured high power impulse magnetron sputtering TiN films grown in the absence of substrate heating and bias, Thin Solid Films (2010), doi: 10.1016/j.tsf.2010.05.064

This is a PDF file of an unedited manuscript that has been accepted for publication. As a service to our customers we are providing this early version of the manuscript. The manuscript will undergo copyediting, typesetting, and review of the resulting proof before it is published in its final form. Please note that during the production process errors may be discovered which could affect the content, and all legal disclaimers that apply to the journal pertain. 
Fully dense, non-faceted 111-textured high power impulse magnetron sputtering TiN films grown in the absence of substrate heating and bias

\section{Lattemann}

Joint Research Laboratory Nanomaterials, Technical University Darmstadt \& Karlsruhe Institute of Technology (KIT), 64287 Darmstadt, Germany

Institute of Nanotechnology, Karlsruhe Institute of Technology (KIT), Postfach 3640, 76021 Karlsruhe, Germany

Plasma \& Coatings Physics Division, IFM Material Physics, Linköping University, SE-581 83 Linköping, Sweden.

\section{U. Helmersson}

Plasma \& Coatings Physics Division, IFM Material Physics, Linköping University, SE-581 83 Linköping, Sweden.

\section{J.E. Greene}

Departments of Materials Science, Physics, and the Frederick Seitz Materials Research Laboratory, University of Illinois, Urbana, Illinois 61801, USA

\section{Abstract}

We demonstrate the deposition of fully dense, stoichiometric TiN films on amorphous $\mathrm{SiO}_{2}$ by reactive high power impulse magnetron sputtering (HiPIMS) in the absence of both substrate heating and applied bias. Contrary to the highly underdense layers obtained by reactive dc magnetron sputtering (dcMS) under similar conditions, the film nanostructure 
exhibits neither intra- or intergrain porosity, exhibiting a strong 111 preferred orientation with flat surfaces. Competitive grain growth occurs only during the early stages of deposition $(<100 \mathrm{~nm})$. The strong differences in the kinetically-limited nanostructural evolution for HiPIMS vs. dcMS are explained by high real-time deposition rates with long relaxation times, high ionization probabilities for $\mathrm{Ti}$, and broad ion energy distributions.

PACS numbers: 811.15.Cd, 81.15.-z, 52.77.-j, 81.30.-t, 68.37.Og, 5240.Hf, 52.70.-m.

Titanium nitride (TiN) thin films, typically deposited by reactive dc magnetron sputtering (dcMS), are widely used as hard, wear, and corrosion resistant coatings on tools and components [1-4]; diffusion barriers in microelectronic devices [5-7]; corrosion and abrasion resistant layers on optical components; and biocompatible layers on medical implants [8-10]. All applications require fully dense films with typical deposition temperatures $\mathrm{T}_{\mathrm{s}}<0.2 \mathrm{~T}_{\mathrm{m}}(<$ $450{ }^{\circ} \mathrm{C}$ ), where $\mathrm{T}_{\mathrm{m}}$ is the TiN melting point, $2949{ }^{\circ} \mathrm{C}$ [11]. Film performance in these applications is largely determined by the nanostructure and, due to the highly anisotropic nature of the physical properties of $\mathrm{NaCl}$-structure transition-metal nitrides, film texture. However, TiN layers grown by conventional reactive dcMS, with little or no substrate bias at $\mathrm{T}_{\mathrm{s}} / \mathrm{T}_{\mathrm{m}}<0.2$, exhibit a columnar structure with both intra- and intercolumnar porosity and mixed 002/111 orientation which gradually evolves over several hundred nm via kineticallylimited competitive growth (the TiN 111 chemical potential $\left|\mu_{111}\right|>\left|\mu_{002}\right|[12]$ ) to a nearly complete 111 preferred orientation with faceted surfaces [13-15].

Densification of reactive dcMS TiN can be obtained by increasing $T_{s} \geq 750{ }^{\circ} \mathrm{C}\left(\mathrm{T}_{\mathrm{s}} / \mathrm{T}_{\mathrm{m}} \geq\right.$ 0.3) resulting in evolution of the low-surface-energy 002 texture [12]. Alternatively, a sufficiently high substrate bias $\left(\mathrm{V}_{\mathrm{s}}>100 \mathrm{eV}\right)$ can be applied at low substrate temperatures, but this leads to large residual defect densities and high in-plane compressive stress with 
mixed 111/002 texture [16-18]. Dense 002-oriented TiN layers, with no significant stress and smooth surfaces, can be obtained using tunable magnetically-unbalanced dcMS sputtering [19] in pure $\mathrm{N}_{2}$ under conditions such that $\mathrm{N}_{2}{ }^{+}$ions [20] are incident at the substrate with energies $\leq 20 \mathrm{eV}$, below the TiN bulk atom displacement threshold, with high ion/metal flux ratios $\left(\mathrm{N}_{2}^{+} / \mathrm{Ti}>5\right)[14,18,21]$.

An approach to obtaining dense 111-textured TiN layers is the combined use of texture inheritance (e.g., the insertion of a highly 0002 oriented Ti interlayer) with low-energy, highflux ion irradiation during deposition [22]. Pseudomorphic forces, operating to minimize local interfacial strain, favor 111 preferred orientation on the $0002 \mathrm{Ti}$ interlayer while lowenergy bombardment promotes densification without producing significant defect-related film stress.

For some diffusion barrier and hard coating applications in which 111 texture is desirable, interfacial layers are not applicable and, due to the requirement of rapid cycling times, the use of a substrate heater and an applied substrate bias is prohibited. In such cases, new deposition processes are required. In this letter, we show that reactive high power impulse magnetron sputtering (HiPIMS) deposition, which can be accomplished in a standard dc magnetron system, simply by changing the power supply, can meet these challenging objectives.

During HiPIMS deposition, high voltages (typically $\sim 500-2400 \mathrm{~V}$, compared to $\sim 300$ $600 \mathrm{~V}$ for dcMS $)$ are applied to the target over short pulses $(\sim 100-1000 \mu \mathrm{s})$ at a low repetition rate $(50-1000 \mathrm{~Hz})$ resulting in duty cycles of only $0.5-5 \%$. The total applied power during the pulse can be several MW, but the time-averaged power is constrained to be approximately the same as that during dcMS in order to minimize target heating. In this way, the plasma density during the "on" part of each cycle can be increased by several orders of magnitude resulting in a much higher fraction of ionized sputtered material than can be obtained in conventional magnetron sputtering [23-25]. Temporal and spatial changes in Ar/N2 plasma pulses during 
HiPIMS sputtering of a $\mathrm{Cr}$ target have recently been characterized using high-speed optical spectroscopy [26].

The deposition experiments reported here are carried out using a circular, $15-\mathrm{cm}-$ diameter, high-purity (99.97\%) Ti disc sputtered in mixed $\mathrm{Ar} / \mathrm{N}_{2}$ atmospheres at a total pressure $\mathrm{P}_{\text {tot }}=0.52 \mathrm{~Pa}(4 \mathrm{mTorr})$ with a $\mathrm{N}_{2}$ partial pressure of $\mathrm{P}_{\mathrm{N} 2}=3.1 \times 10^{-3} \mathrm{~Pa}\left(2.3 \times 10^{-5}\right.$ Torr). The substrates are amorphous, 4-nm-thick, $\mathrm{SiO}_{2}$ layers on highly-polished, B-doped, $1 \Omega$-cm Si(001) wafers, $1 \times 1 \mathrm{~cm}^{2}$, mounted $10 \mathrm{~cm}$ below the center of the target. Deposition is carried out at ambient temperature with no substrate heater. The target voltage, $\mathrm{V}_{\mathrm{T}}=-690 \mathrm{~V}$, is applied over pulse lengths of $100 \mu$ s with a frequency of $100 \mathrm{~Hz}$, corresponding to a duty cycle of $1 \%$. The time-averaged TiN deposition rate is $0.05 \mathrm{~nm} \mathrm{~s}^{-1}$.

Ion irradiation conditions during film growth are probed by removing the substrate holder and measuring the composition and energy distribution of ions incident at a time- and energyresolved mass spectrometer (see ref. 27 for further details) located $27 \mathrm{~cm}$ below the target. The measured energy distributions underestimate the actual impact energies at the substrate due to additional gas-phase collisions between the substrate plane and the entrance to the spectrometer.

Figure 1 shows typical cross-sectional and plan-view transmission electron microscopy (XTEM and TEM) images from TiN films grown by reactive HiPIMS. The low resolution micrographs are underfocused in order to enhance the contrast for detecting underdense regions. Figure 1a is a plan-view micrograph of a 400-nm-thick polycrystalline layer consisting of 111 and 002 grains, with average size $25-30 \mathrm{~nm}$, and fully dense boundaries.

Multiple high-resolution TEM (HR-TEM) images from layers with thicknesses less than $10 \mathrm{~nm}$ reveal the presence of approximately equal number densities of 111 and 002 grains, indicating similar nucleation barriers for the two orientations. Figure $1 \mathrm{~b}$ is a typical HR-TEM image corresponding to a 30-nm-thick TiN layer consisting primarily of 111 , with a few 002 , 
grains. Some examples are labeled. Contrary to reactive dcMS TiN layers, the HiPIMS films, even at this low thickness, are fully dense. Fast Fourier transform patterns (FFT) obtained from cross-sectional regions, with a diameter of $\sim 30 \mathrm{~nm}$, centered at film thicknesses near 10 nm consist of diffraction spots along 111 and 002 rings. Figure 1c is a typical example exhibiting strong 111 and 002 reflections, with a spread of approximately $\pm 10^{\circ}$ relative to the substrate normal, along the growth direction.

The XTEM image in Fig. 1d shows that after an initial $~ 100-n m-$ thick region of competitive 002/111 growth due to large differences in cation diffusivities, and hence residence times, on differently oriented surfaces [12], the surviving, primarily 111, columns, grow essentially straight up throughout the remainder of the film thickness. A rare example of two 002 columns merging above a terminated 111 column is illustrated in Fig. 1e. The more common merging of 111 columns can be seen in Fig. 1b. Average column widths, obtained from lower-resolution micrographs, are $25 \pm 2$ and $30 \pm 2 \mathrm{~nm}$ for 111 and 002 oriented columns, respectively. HiPIMS TiN film surfaces are smooth and unfacetted, again contrary to what is observed for dcMS TiN layers grown on unbiased substrates at low temperatures. Selected-area electron diffraction (SAED) patterns from film regions with thickness $>100 \mathrm{~nm}$ reveal strong 111 preferred orientation as shown in the inset in Fig. 1d. The volume ratio of 111 grains, $111 /(111+002)$, in 400-nm-thick films is estimated from $\mathrm{x}$-ray diffraction (XRD) patterns, based upon the Jandel PEAKFIT code [28] employing combined Gaussian/Lorentzian peak fits, to be $76 \%$.

While low-energy ion irradiation collisionally enhances $\mathrm{Ti}$ adatom mean free paths on both 111 and 002 surfaces, the dominant effect controlling TiN nanostructure evolution under these growth conditions is the irradiation-induced change in steady-state surface chemistry. The high $\mathrm{N}^{+}$and $\mathrm{N}_{2}^{+}$fluxes increase $\mathrm{N}$ coverages $\theta_{\mathrm{N}}$ on non-polar 002 surfaces, thereby greatly decreasing $\mathrm{Ti}$ adatom mobilities as well as $\mu_{002}$, through formation of $\mathrm{TiN}_{\mathrm{x}}$ 
admolecules $[12,29] . \theta_{\mathrm{N}}$, and hence $\mu_{111}$, on polar 111 surfaces, remains constant since 111 is already $\mathrm{N}$ terminated [12]. Thus, there is a transition in the relative values of the chemical potentials such that $\left|\mu_{002}\right|<\left|\mu_{111}\right|$ leading to the competitive evolution of 002 , rather than 111 , texture.

Figure 2 summarizes the results of time-averaged measurements, averaged over several pulses, of ion energy distributions (IEDs) at the substrate during reactive TiN HiPIMS. The ion energies are slightly underestimated since the mass spectrometer is located $27 \mathrm{~cm}$ from the target, while the substrate is at $10 \mathrm{~cm}$, resulting in additional gas-phase collisions before entering the mass spectrometer orifice. $\mathrm{Ti}^{+}, \mathrm{N}^{+}, \mathrm{Ti}^{2+}, \mathrm{Ar}^{+}, \mathrm{N}_{2}{ }^{+}$, and $\mathrm{Ar}^{2+}$ ions were detected with a narrow energy distribution and a peak near $1 \mathrm{eV} /$ charge. In addition, $\mathrm{Ti}^{+}, \mathrm{N}^{+}$, and $\mathrm{Ti}^{2+}$ ions have a secondary wider-energy distribution with a weak maximum near $12 \mathrm{eV} /$ charge. Doubly ionized $\mathrm{Ar}^{2+}$ and $\mathrm{Ti}^{2+}$ account for $33 \%$ and $10 \%$ of the total population of $\mathrm{Ar}$ and $\mathrm{Ti}$ ions, respectively, and since the IEDs are plotted as energy per charge, their absolute energies are a factor of two higher. Moreover, Ti ions have been shown to account for up to $90 \%$ of the total HiPIMS Ti flux at the substrate [23]. Thus, significant ion irradiation of the growing film during occurs during HiPIMS deposition, even in the absence of an applied substrate bias.

The advantages of HiPIMS compared to dcMS - dense columnar structure, shorter competitive growth region, wider columns, and flat surfaces - for TiN layers reactively deposited on substrates with no applied heating or bias derive primarily from major differences in the mechanisms by which the two techniques function. Magnetron sputtering is carried out at relatively low powers in a steady-state plasma, whereas HiPIMS is operated at very high powers using low-frequency, short pulses with low duty cycles. The latter gives rise to very high real-time deposition rates during the on pulse, long surface relaxation times during the off pulse, an increase in the energy distribution of ions neutralized and reflected 
from the target, and enhanced rarefaction of the sputtering gas directly in front of the target $[30,31]$ giving rise to high cation (primarily $\mathrm{Ti}^{+}$and $\mathrm{Ti}^{2+}$ ) ion fluxes incident at the substrate.

The instantaneous deposition rate, $5 \mathrm{~nm} / \mathrm{s}$, during the on time of the HiPIMS cycle is 100x that of the time-averaged deposition rate. This, combined with growth on unheated substrates, results in a short average nucleation length with a high nucleation rate giving rise to an initially high island density and small island size [32]. Continued deposition then leads to rapid island overgrowth, following island coalescence, with a correspondingly narrow competitive growth region $(\sim 100 \mathrm{~nm})$ as shown by XTEM (see, e.g. Fig. 1d). Texture evolves toward 111, even though the 001 surface energy is lower [12], due to kinetic limitations associated with the higher cation surface diffusivity on $\operatorname{TiN}(001)$ than $\operatorname{TiN}(111)$ as discussed above.

The columns and intercolumnar boundaries observed in our low-temperature HiPIMS films are dense, even in the absence of an applied substrate bias, due to intense low-energy ion irradiation from $\mathrm{Ti}^{+}, \mathrm{N}^{+}$, and $\mathrm{Ti}_{2}{ }^{+}$ions with a relatively wide energy distribution having a weak maximum near $12 \mathrm{eV} /$ charge together with $\mathrm{Ti}^{+}, \mathrm{N}^{+}, \mathrm{Ti}_{2}{ }^{+}, \mathrm{Ar}^{+}, \mathrm{N}_{2}{ }^{+}$, and $\mathrm{Ar}^{2+}$ ions having a narrow energy distribution and a sharp peak near $1 \mathrm{eV} /$ charge. The primary ion-induced densification mechanisms, as demonstrated by molecular dynamics simulations $[33,34]$, are fast violent effects including forward sputtering into underdense regions, recoil events, and knock-on adatom surface migration, together with slower multi-atom collective lattice relaxation events, due to forward momentum imparted along surface cascades, into voided regions. The former occurs over time scales of order ps, while relaxation events take place over much longer time scales.

In summary, we have demonstrated that dense, relatively large grained, highly textured TiN films can be grown by reactive HiPIMS in the absence of substrate heating and biasing. Competitive 002 and 111 grain growth, which occurs in the early stages of deposition is 
essentially finished by a film thickness of $\sim 100 \mathrm{~nm}$ giving rise to layers with a dense 111 preferred orientation and flat surfaces. Based upon the combination of deposition rate, HRTEM, XRD, and ion energy distribution measurements at the substrate, we conclude that the key features distinguishing HiPIMS from dcMS are the very high instantaneous deposition rate during the on time of the HiPIMS deposition pulse leading to short nucleation lengths and, hence, high initial island densities, together with intense low-energy ion irradiation of the growing film by $\mathrm{Ti}^{+}$and $\mathrm{Ti}^{2+}$ (in addition to $\mathrm{Ar}^{+}, \mathrm{N}^{+}$, and $\mathrm{N}_{2}^{+}$) providing densification via ion-bombardment-induced adatom migration. Cation deposition is primarily from Ti ions, especially during the latter part of the deposition pulse as Ar is swept away from the region immediately in front of the target due to gas rarefaction caused by the high instantaneous target powers. This leads to efficient ionization of sputtered Ti atoms. Long relaxation times following the short, low-frequency deposition pulses also play a role in film densification.

The authors gratefully acknowledge the financial support during the course of this research from the Swedish Research Council, the Swedish Foundation for Strategic Research, and the U.S. Department of Energy, Division of Materials Science, grant DEFG0291ER45439 through the University of Illinois Frederick Seitz Materials Research Laboratory (J.E.G.).

\section{References}

1. J.-E. Sundgren, Thin Solid Films 128 (1985) 21.

2. H. Ljungcrantz, M. Oden, L. Hultman, J.E Greene, and J.-E. Sundgren, J. Appl. Phys. 80 (1996) 6725.

3. H. Rebenne and D. Bhat, Surf. Coat. Technol. 63 (1994) 1.

4. W. Chou, G. Yu, and J. Huang, Surf. Coat. Technol. 149 (2002) 7. 
5. G. Gagnon, J. Currie, J. Brebner, and T. Darwall, J. Appl. Phys. 79 (1996) 7612.

6. P. Patsalas, C. Charitidis, S. Logothetidis, C. Dimitriadis, and O. Valassiades, J. Appl. Phys. 86 (1999) 5296.

7. G. Chen, J. Guo, C. Lin, G. Hsu, L. Yang, and J. Fang, J. Vac. Sci. Technol. A 20 (2002) 479.

8. R. Hübler, Surf. Coat. Technol. 116-119 (1999) 1111.

9. L. Cyster, D. Grant, K. Parker, and T. Parker, Biomol. Eng. 19 (2002) 171.

10. S. Mukherjee, F. Maitz, M. Pham, E. Richter, F. Prokert, and W. Moeller, Surf. Coat. Technol. 196 (2005) 312.

11. L.E. Toth, Transition Metal Carbides and Nitrides, Academic Press. New York, 1971.

12. D. Gall, S. Kodambaka, I. Petrov, J.E. Greene, J. Appl. Phys. 93 (2003) 9086.

13. L. Hultman, W.-D. Munz, J. Musil, S. Kadlec, I. Petrov, and J.E. Greene, J. Vac. Sci. Technol. A 9 (1991) 434.

14. L. Hultman, J.-E. Sundgren, J.E. Greene, D. Bergstrom, and I. Petrov, J. Appl. Phys. 78 (1995) 5395.

15. F.H. Baumann, D.L. Chopp, G.H. Gilmer, J.E. Greene, H. Huang, S. Kodambaka, I. Petrov, P. O'Sullivan, and T. Diaz de la Rubia, MRS Bull. 26 (2001) 182.

16. G. Hakansson, J.-E. Sundgren, D. McIntryre, J.E. Greene, and D.-W. Munz, Thin Solid Films 153 (1987) 55.

17. I. Petrov, L. Hultman, U. Helmersson, J.-E. Sundgren, and J. E. Greene, Thin Solid Films 169 (1989) 299.

18. I. Petrov, P.B. Barna, L. Hultman, and J.E. Greene, J. Vac. Sci. Technol. A 21 (2003) S117.

19. I. Petrov, F. Adibi, J.E. Greene, W.D. Sproul, W.-D. Munz, J. Vac. Sci. Technol. A 10 (1992) 3283. 
20. I. Petrov, A. Myers, J.E. Greene, and J.R. Abelson, J. Vac. Sci. Technol. A 12 (1994) 2846.

21. J. E. Greene, J.-E. Sundgren, L. Hultman, I. Petrov, and D. B. Bergstrom, Appl. Phys. Lett. 67 (1995) 2928.

22. J.-S. Chun, I. Petrov.amd J.E. Greene, J. Appl. Phys. 86 (1999) 3633.

23. J. Bohlmark, A. Ehiasarian, C. Christou, J. Alami, and U. Helmersson, J. Vac. Sci. Technol. A 23 (2005) 18.

24. V. Kouznetsov, K. Macak, J. Schneider, U. Helmersson, and I. Petrov, Surf. Coat. Technol. 122 (1999) 290.

25. U. Helmersson, M. Lattemann, J. Bohlmark, A. Ehiasarian, and J. Gudmundsson, Thin Solid Films 513 (2006) 1.

26. M. Hala, N. Viau, O. Zabeida, J. E. Klemberg-Sapieha, and L. Martinu, J. Appl. Phys.107 (2010) 043305.

27. J. Bohlmark, M. Lattemann, J. Gudmundsson, A. Ehiasarian, Y. Aranda Gonzalvoand, N. Brenning, and U. Helmersson, Thin Solid Films 515 (2006) 1522.

28. http://www.spss.com.

29. M.A. Wall, D.G. Cahill, I. Petrov, D. Gall, and J.E. Greene, Surf. Sci. 581 (2005) L122.

30. D.W. Hoffman, J. Vac. Sci. Technol. A 3 (1985) 561.

31. S.M. Rossnagel, J. Vac. Sci. Technol. A 6 (1988) 19.

32. J. M. Warrender, M.J. Aziz, Phys. Rev. B 76 (2007) 045414, refs therein.

33. K.-H Müller, Phys. Rev. B 35 (1987) 7906.

34. K.-H Muller, Surf. Sci. 184 (1987) L375. 


\section{Figure captions}

Fig. 1: Under-focused bright-field TEM micrographs revealing the nanostructure of TiN films grown by HiPIMS in the absence of substrate heating and bias: (a) plan view image of a 400nm-thick layer; (b) HR-TEM image and (c) a FFT pattern, centered at a thickness of $10 \mathrm{~nm}$, from a 30-nm-thick layer; and (d) and (e) XTEM images. An SAED pattern is shown as an inset in (d).

Fig. 2: (Color online) Energy distributions of ions incident at the substrate plane during HIPIMS reactive sputter deposition of TiN. 
Figure 1
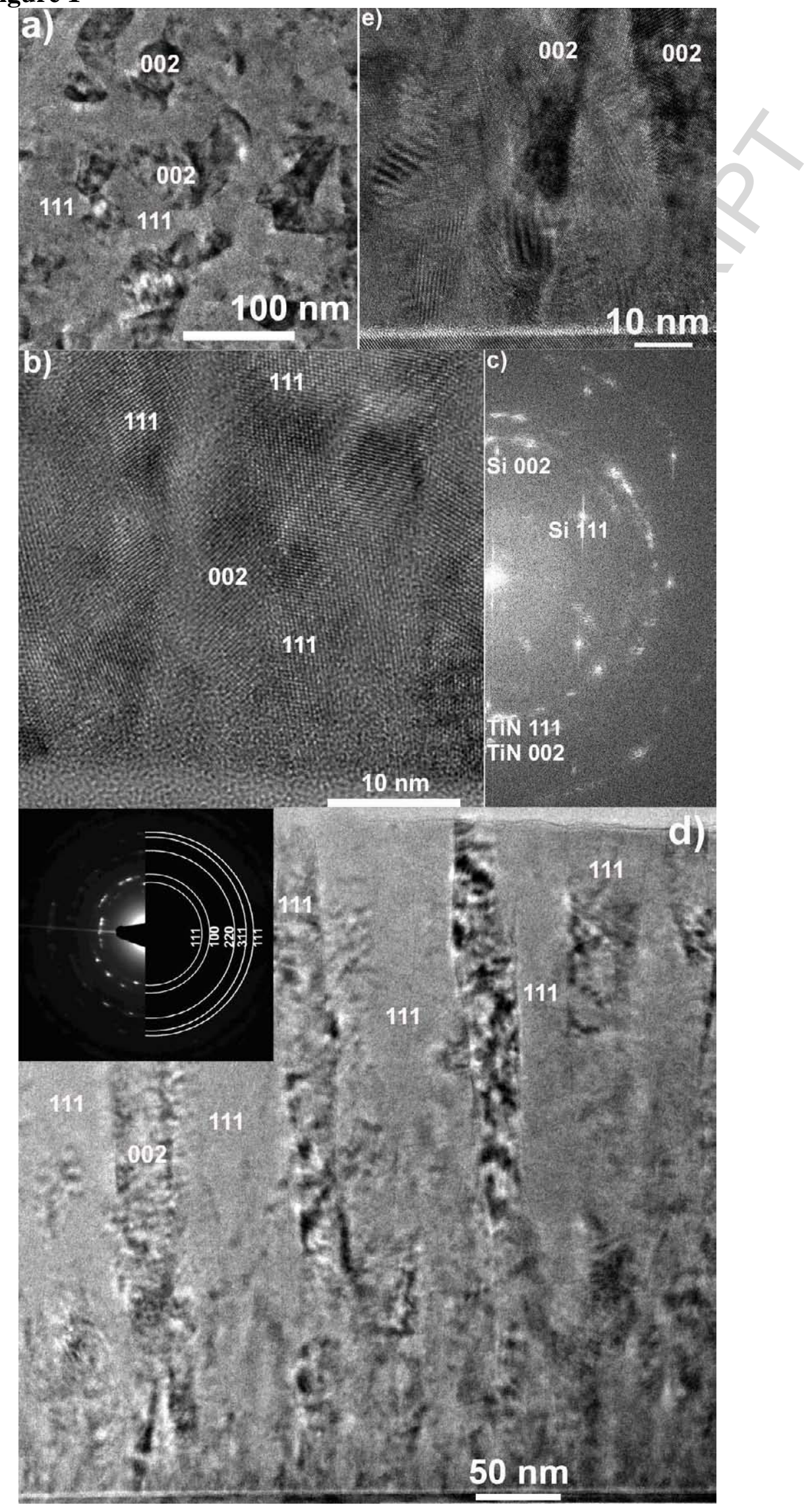


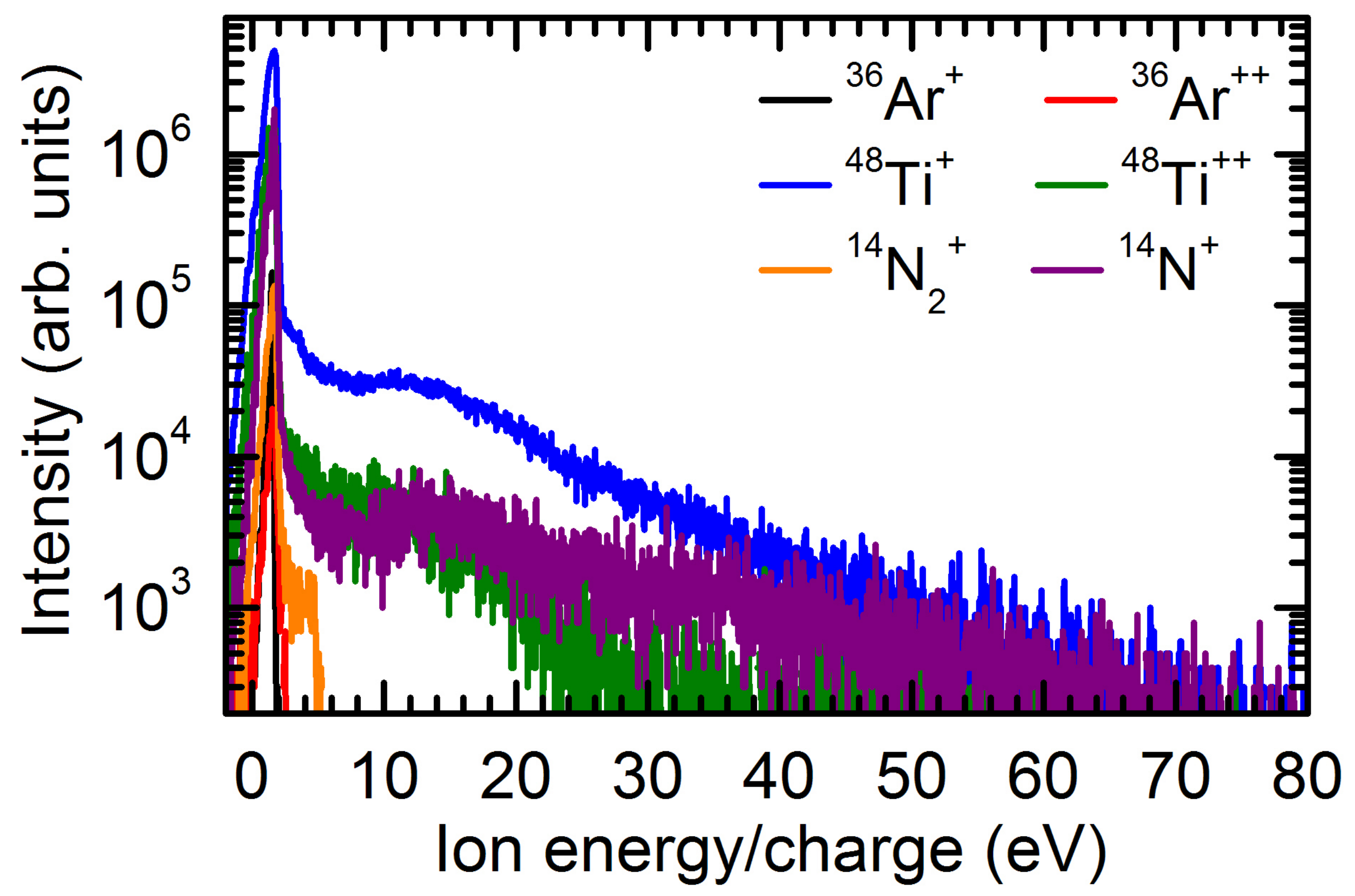

